\title{
The burden of intentional injuries in Mwanza City, north-western Tanzania: a tertiary hospital survey
}

\author{
PHILLIPO L. CHALYA* and JAPHET M. GILYOMA \\ Department of Surgery, Catholic University of Health and Allied Sciences-Bugando, Mwanza, Tanzania
}

\begin{abstract}
Intentional injuries are an emerging silent epidemic in developing countries and contribute significantly to global injury burden. A descriptive prospective study was conducted to establish the prevalence, contributing factors, injury pattern and treatment outcome of intentional injuries at Bugando Medical Centre in North-western Tanzania. Data was collected using a pre-tested, coded questionnaire and analyzed using SPSS software version 17.0. A total of 1642 (23.7\%) patients with intentional injuries were studied. Of these, $97.7 \%$ resulted from interpersonal violence (homicide) and $2.3 \%$ were self-inflicted (suicide). Males outnumbered females by a ratio of 2.2:1. Their median age was 24 years. The majority of injuries (53.5\%) occurred at home. Criminal violence was the most common reason for intentional injuries accounting for $52.1 \%$ of cases. In women, domestic violence was responsible for $64.6 \%$ of the admissions. Poverty, lack of education, unemployment and alcohol abuse were the most common contributing factors to intentional injuries. Blunt and sharp objects $(48.6 \%)$ were the most common weapons used. Gunshot injuries were recorded in $11.6 \%$ of cases. The head/neck was commonly affected in $49.2 \%$. Soft tissue injuries (87.3\%) were the most frequent type of injuries. The majority $(90.1 \%)$ of patients were treated surgically. Complication rate was $15.0 \%$.The median hospital stay was 26 days (range 1 day to 114 days). Patients with long bone fractures and those who had complications stayed longer in the hospital $(P<0.001)$. Mortality rate was $13.3 \%$. The mortality rate was significantly high in patients with severe injuries (Injury Severity Score > 15), severe head injuries and those who needed intensive care unit admissions and ventilatory support $(P<0.001)$. Intentional injuries are an emerging but neglected epidemic in Mwanza City and contribute significantly to high morbidity and mortality. Urgent preventive measures targeting at the root causes of violence such as poverty, unemployment, and alcohol abuse will reduce the incidence of these injuries in our setting.
\end{abstract}

Keywords: intentional injuries, prevalence, contributing factors, pattern, treatment, hospital, Tanzania

\section{Introduction}

Intentional injuries, defined as injuries resulting from interpersonal or self-inflicted violence constitute a growing but neglected epidemic in developing countries and contribute significantly to the global injury burden (Nordberg, 2000; Zhao et al., 2004; Stone et al., 2006; Omoniyi \& Eme, 2007). Intentional injuries present a threat to the physical and psychological well being of victims and it is associated with substantial emotional and financial burden on community and hospital resources (Said et al., 2002; Ben et al., 2008). The problem is increasing at a fast rate in developing countries partly because of increasing conflict over limited resources, unemployment, easy access to firearms, alcohol and substance misuse and increased crime rates (Solagbem, 2003; Onuminya \& Ohwowhiagbese, 2005; Mugala \& Imataa, 2007; Kobusingye, 2008). The socioeconomic impact of intentional injuries has received a great deal of interest because of the resultant loss of productive years and the drain on limited health care funds (Cubbin \& Smith, 2002; Mugala \& Imataa, 2007;

* Correspondence: Phillipo L. Chalya; E-mail: drphillipoleo@yahoo.com 
Kobusingye, 2008). Victims of intentional injury represent a socially and economically disadvantaged population. Their medical care is poorly funded and physicians who provide care are marginally compensated (Luna, 2001; Warers et al., 2004).

Funding the medical care for victims of intentional injuries has become an increasingly important issue for trauma care delivery systems (Stone et al, 2006; Kobusingye, 2008). Intentional injuries are costly as their emergency treatment, hospitalization and long term care divert scarce resources from other development priorities (Luna, 2001; Krug et al., 2002; Kobusingye, 2008). In most of developing countries like Tanzania, more than $80 \%$ of victims of intentional trauma have no definable source of private or governmental health care insurance at the time of their injury (Mutasingwa \& Aaro, 2001; Moshiro et al., 2005). Poverty, discrimination, lack of education, and lack of employment opportunities have been reported to be important risk factors for intentional injuries in developing countries (Solagbem, 2003; Onuminya \& Ohwowhiagbese, 2005; Kobusingye, 2008).

In Tanzania, like many other developing countries, the occurrence and health impact of intentional injuries has not received a great deal of attention mainly due to lack of awareness of the magnitude of the problem. Information on intentional injuries is scarce and unreliable and reports that reach the Ministry of Health from health institutions are inaccurate, due to major under-reporting and misclassification (Museru et al., 1998; Mutasingwa \& Aaro, 2001; Moshiro et al., 2005). Intentional injuries are an emerging silent epidemic in Mwanza City in Tanzania and claim the lives of many of the young persons and threaten the health and well-being of many persons of all age groups.

There is paucity of information in most developing countries on both morbidity and mortality due to intentional injuries where greater emphasis has been placed on injuries related to road traffic crushes, which are more common. Intentional injuries though have become an epidemic and burden of disease in Mwanza City, have not received the attention they deserve. The public policy responses to this problem have been muted, probably because of lack of local data regarding the problem. This study aimed at providing local data regarding the magnitude of the problem, contributing factors, pattern of injuries and outcome of these patients. This data provides basis for establishment of prevention strategies as well as treatment guidelines.

\section{Material and Methods}

\section{Study setting and design}

Between January 2010 and December 2010, a descriptive prospective study involving victims of intentional injuries was conducted at the Accident and Emergency (A \& E) department of Bugando Medical Centre (BMC) in north-western Tanzania. BMC is a consultant, tertiary care and teaching hospital for the Catholic University of Health and Allied Sciences (CUHAS)-Bugando and other paramedics. It has a bed capacity of 1000 and serves approximately 13 million people from six regions namely Mwanza, Kagera, Mara, Shinyanga, Kigoma and Tabora.

\section{Study subjects}

The study subjects included all patients of all age groups and gender who presented with intentional injuries and who consented for the study. Patients who were unable to give information and had no next of kin to consent were excluded from the study. Recruitment of patient to participate in the study was done at the A\&E department after primary and 
secondary surveys done by the admitting surgical team. Patients were screened for inclusion criteria and those who met the inclusion criteria were requested to consent before being enrolled into the study. All patients recruited into the study were first resuscitated in the A\&E department according to Advanced Trauma Life Support (ATLS). From the A \& E department patients were taken into the surgical wards or the intensive care unit (ICU) from where necessary investigations were completed and further treatment started.

\section{Data collection}

Data were collected using a pre-tested, coded questionnaire and included demographic details (i.e. age, sex, occupation, education, and socio-economic status), circumstances of the injury (i.e. time of injury, place of injury, reasons and contributing factors for the injury, weapon used, pre-hospital care, timing of medical care), characteristics of injury (mechanism of injury, body region affected, type of injury, severity of injury), treatment parameters and outcome measures (length of hospital stay, mortality and complications). The amount of hospital bill for each patient was recorded on discharge. Patients were followed up till discharge or death. Complications were adequately treated accordingly.

\section{Data analysis}

Statistical data analysis was done using SPSS software version 17.0 (SPSS, Inc, Chicago, IL). Data was summarized in form of proportions and frequent tables for categorical variables. Continuous variables were summarized using means, median, mode and standard deviation. P-values were computed for categorical variables using Chi-square $\left(\chi^{2}\right)$ test and Fisher's exact test depending on the size of the data set. Independent student $t$-test was used for continuous variables. Multivariate logistic regression analysis was used to determine predictor variables that are associated with outcome. A p-value of less than 0.05 was considered to constitute a statistically significant difference.

\section{Ethical consideration}

Ethical approval to conduct the study was obtained from the CUHAS/BMC joint institutional ethic review committee before the commencement of the study. Patients who met the inclusion criteria were requested to sign a written informed consent before being enrolled into the study.

\section{Results}

\section{Socio-demographic data}

A total of 6,934 trauma patients were seen at the A \& E department during the study period, of whom 1,642 (23.7\%) patients had intentional injuries, and these made the study population. Males were 1,128 (68.7\%) and females were $514(31.3 \%)$ with the male to female ratio of 2.2:1. Their ages ranged from 3 to 76 years (median $=24$ years). The modal age group was 21-30 years. The vast majority of patients $(1,351,82.3 \%)$ had primary or no formal education and most of them $(1,302,79.3 \%)$ had no employment. The victims came from all the townships of Mwanza City with 1,481 (90.2\%) victims coming from low-income areas (high density areas) and the remaining 161 (9.8\%) victims came from high-income areas (low density areas). Only 63 (3.8\%) of the victims had definable source of private or governmental health care insurance at the time of their injury. 


\section{Circumstances of injury}

The majority of injuries $(879,53.5 \%)$ occurred at home (Table 1$)$. The vast majority $(97.7 \%$; $\mathrm{N}=1,604$ ) of intentional injuries comprised of interpersonal violence whereas self-inflicted injuries (attempted and completed suicides) occurred in $38(2.3 \%)$ of the cases. History of alcohol consumption either by the victim or perpetrator was reported in 1,104 (67.2\%) of the cases and it was the perpetrator of the violence who was often under the influence of alcohol.

Table 1: Sex distribution according to the place of injury

\begin{tabular}{lccc}
\hline Place of injury & Males & Females & Total \\
\hline Home & $512(31.2 \%)$ & $367(22.1 \%)$ & $879(53.5 \%)$ \\
Along the way & $340(20.7 \%)$ & $30(1.8 \%)$ & $370(22.5 \%)$ \\
Drinking place & $214(13.0 \%)$ & $102(6.2 \%)$ & $316(19.2 \%)$ \\
Work place & $48(2.9 \%)$ & $9(0.5 \%)$ & $57(3.5 \%)$ \\
Others & $14(0.9 \%)$ & $6(0.3 \%)$ & $20(1.2 \%)$ \\
Total & $1128(68.7 \%)$ & $514(31.3 \%)$ & $1642(100 \%)$ \\
\hline
\end{tabular}

Criminal violence (thievery, fighting, assaults, sexual abuse, suicide) was the most the common (52.1\%; $\mathrm{N}=856)$ reason for intentional injuries. This was followed by domestic conflicts and other conflicts in $397(24.2 \%)$ and $372(22.7 \%)$ of cases respectively. The reason was not known in $17(1.0 \%)$ of cases. The majority of females were victims of domestic conflicts accounting for $332(64.6 \%)$ of cases and the attacker were mainly husbands and expartners. The attacker/ perpetrator was known to the victim (friends, husbands, ex-partners, relatives, neighbours) in $1084(66.0 \%)$ of cases and in the remaining 558 (34.0\%) the attacker was not known. In cases of thievery the attacker was not known in all the cases.

The majority of injuries occurred during night hours in 1,228 (74.8\%) of cases and in the remaining $414(25.2 \%)$ patients occurred during the day. In terms of timing, the most dangerous time for domestic violence was from 18 to 21 hours. Generally more than $50 \%$ of domestic violence occurred before 21 hours and most criminal violence from 21 hours onwards.

The majority of patients $(60.0 \% ; \mathrm{N}=986)$ arrived at the hospital within 24 hours. Thirty-five (2.1\%) patients had pre-hospital care. The majority $(98.7 \% ; \mathrm{N}=1,621)$ of patients were brought in by relatives, Good Samaritan and police in. Only $8(0.5 \%)$ were brought in by ambulance and the remaining $21(1.3 \%)$ patients came themselves.

\section{Injury characteristics}

Blunt objects (including stones, iron bars, sticks, bottles) and sharp objects (machetes, knives, axes, screw drivers) were the most common weapons through which violence was inflicted accounting for 798 (48.6\%) of cases. Fists, slaps and kicks were used to inflict violence in 627 $(38.2 \%)$ of cases. The use of guns to inflict violence was recorded in $190(11.6 \%)$ of cases. Spilling with hot liquids or chemical were the means through which violence was inflicted in $27(1.6 \%)$ of cases.

Blunt injuries were the most common mechanism of injuries (954; $\mathrm{N}=58.1 \%$ ) followed by either penetrating injuries (cut wounds, stabbing, gunshot) or both in 661 (40.3\%) patients. Spilling with hot liquids or chemical was the mechanism of injury in $27(1.6 \%)$ of victims. The head/neck and musculoskeletal (mainly upper limbs) were the most common body regions affected in $808(49.2 \%)$ and 711 (43.3\%) respectively (Table 2 ). 
Table 2: Site of injury among victims

\begin{tabular}{lll}
\hline Site of injury & Frequency & Percentage \\
\hline Head/neck & 808 & 49.2 \\
Musculoskeletal & 711 & 43.3 \\
Chest & 637 & 38.8 \\
Abdomen & 621 & 37.8 \\
Ocular & 38 & 2.3 \\
Spines & 8 & 0.5 \\
Pelvis & 5 & 0.3 \\
Multiple sites & 92 & 5.6 \\
\hline
\end{tabular}

Musculoskeletal injuries included soft tissue injuries (bruises, laceration, abrasion and contusions) in $684(96.2 \%)$ injuries and fractures in 206 (28.9\%) injuries. In patients who had head injuries, 265 (32.8\%) patients had mild head injuries (Glasgow coma scale (GCS) = 1315), $344(42.6 \%)$ had moderate head injuries (GCS=9-12) and $199(24.6 \%)$ had severe head injuries (GCS=3-8). Injury Severity Score (ISS) was recorded in 92 (5.6\%) polytraumatized patients. Of these, $57(62.0 \%)$ patients had mild to moderate injury (ISS $\leq 16)$ and the remaining $35(38.0 \%)$ had severe injuries. The majority of patients $(1457,88.7 \%)$ had systolic blood pressure (SBP) $\geq 90 \mathrm{mmHg}$ on admission whereas the remaining $(185,12.7 \%)$ patients had SBP $<90 \mathrm{mmHg}$. Soft tissue injuries (wounds) were the most common type of injuries affecting $1,434(87.3 \%)$ of cases (Table 3$)$.

Table 3: Types of injuries sustained

\begin{tabular}{lcc}
\hline Type of injury & Frequency & Percentage \\
\hline Soft tissue injuries (wounds) & 1434 & 87.3 \\
Long bone fractures /dislocations & 206 & 28.9 \\
Rib fractures & 30 & 1.8 \\
Hemothorax & 61 & 3.7 \\
Pneumothorax & 25 & 1.5 \\
Pneumohemothorax & 16 & 0.9 \\
Visceral injuries & 27 & 1.6 \\
Burn injuries & 27 & 1.6 \\
Other injuries & 103 & 6.3
\end{tabular}

\section{Treatment modalities}

Table 4: Types of surgical procedure performed $(\mathrm{N}=1479)$

\begin{tabular}{lcc}
\hline Types of surgical procedure & Frequency & Percentage \\
\hline Wound debridement & 1428 & 96.6 \\
POP/EF/ORIF & 187 & 12.6 \\
Underwater seal drainage & 64 & 4.3 \\
Explorative laparotomy & 18 & 1.2 \\
Limb amputation & 15 & 1.0 \\
Skin grafting & 10 & 0.7 \\
Other minor operations & 56 & 3.8 \\
\hline
\end{tabular}

Keys: $\mathrm{POP}=$ Plaster of Paris, $\mathrm{EF}=$ External Fixators, ORIF $=$ Open reduction and internal fixation

The vast majority (90.1\%; $\mathrm{N}=1479)$ of patients were treated surgically and the remaining 163 $(9.9 \%)$ were treated by non-operative approach (conservatively) with intravenous fluids, analgesics, antibiotics, tetanus toxoid prophylaxis, blood transfusion, wound dressing etc. 
Wound debridement was the most common surgical procedure performed in $96.6 \%$ of cases (Table 4). Most patients (79.2\%; N=1,301) were admitted in the general and orthopaedic surgical wards and the remaining 341 (20.8\%) in the Intensive Care Unit (ICU). Of those who were admitted in the ICU, $112(32.8 \%)$ patients needed ventilatory support.

\section{Treatment outcome}

A total of 356 complications developed in 247 (15.0\%) patients (Table 5). The overall median length of hospital stay (LOS) was 26 days (range 1-114 days). The LOS for non-survivors ranged from 1-16 days (median $=3$ days). Patients with long bone fractures and those who had complications stayed longer in the hospital $(P<0.001)$.

A total of 219 patients died giving a mortality rate of $13.3 \%$. According to multivariate logistic regression analysis, the mortality rate was significantly high in patients with severe injuries (ISS $>15$ ), severe head injuries and those who needed ICU admissions and ventilatory support $(P<0.001)$.

Table 5: Complications among victims $(\mathrm{N}=356)$

\begin{tabular}{|c|c|c|}
\hline Complications & Frequency & Percentage \\
\hline Wound sepsis & 98 & 26.5 \\
\hline Complications of long bone fractures & 32 & 9.0 \\
\hline Complications of abdominal surgery & 5 & 1.4 \\
\hline Limb re-amputation & 4 & 1.1 \\
\hline Skin grafting failure & 3 & 0.8 \\
\hline Emphysema thoracis & 3 & 0.8 \\
\hline Pneumonia & 2 & 0.6 \\
\hline
\end{tabular}

The amount of hospital bill for each patient ranged from US\$ 56- 305.

\section{Discussion}

In this study the prevalence of intentional injuries in Mwanza City was 23.7\% which is comparable to what was reported in Ethiopia (23.6\%) and Uganda (22.3\%) by Wolde et al. (2008) and Multo et al. (2010), respectively, but significantly higher than what was reported in Zambia (1.28\%) (Mugala \& Imataa (2007). This observation reflects differences in study methodology and risk factors for intentional injuries among different study settings. The prevalence in the present study may actually be an underestimate and the magnitude of the problem may not be apparent because the study did not include patients who did not report or who were not admitted to Bugando Medical Centre. Furthermore, persons who die at the scene and did not reach the hospital were not included in the study. Several other cases may also have been treated in private hospitals which were also not included in the present study. Patients who were not eligible for the study were also excluded. A better picture of the prevalence of intentional injuries in Mwanza requires comprehensive data including police records, hospital admissions, and mortuary records. Better data could support useful policy guidance and help abate interpersonal violence and their related morbidity and mortality. The world report on violence and health has shown that the pattern of intentional injuries varies geographically and according to the socio-economic status. In developed countries, suicides account for the largest share of the intentional injury burden, whereas in developing regions, violence and war are the major sources (Krug et al., 2002). This is 
reflected in the low rate of intentional injuries in patients in Mwanza. The reason for this observation could not be established.

Increased incidence of intentional injuries in most developing countries has been attributed to poverty, unemployment, easy access to firearms, alcohol and substance misuse, political instability and unequal distribution of wealth (Solagbem, 2003; Onuminya \& Ohwowhiagbese, 2005; Kobusingye, 2008). This is reflected in the high rate of intentional injuries in our patients, majority of whom, were unemployed and uneducated and the majority of victims came from low-income areas of the city and had no definable source of health care insurance at the time of their injury. Socioeconomic class and poverty have been reported to influence the occurrence and outcomes of intentional injuries through physical, social, psychological, educational and occupational variables, as well as other societal factors, such as the existence of social capital and social networks (Cubbin \& Smith, 2002). Once injured, poorer people may have less access to high-quality emergency medical and rehabilitative services, and the costs of health care and lost earning capacity have a severe negative impact on their financial situation. A strong association between alcohol use and criminal activity is well documented in literature (Mugala \& Imataa, 2007). In the present study, alcohol was involved in two thirds of the cases. In the majority of the cases it was the perpetrator of the violence who was under the influence of alcohol. Thieves tended to take alcohol before they robbed their victims.

In agreement with other studies (Lule et al, 2006; Mugala \& Imatar, 2007; Ben et al., 2008), most of intentional injuries in this study commonly affected young adult males, who are still in their productive period of life. Male preponderance in this age group is attributable to their active participation in risk taking behaviours and their frequent involvement in interpersonal violence. This has great economic impact since these are people in their most productive years and the injuries impose a considerable burden on their families and the society as a whole.

Criminal violence mainly thievery and assaults was the most common reason for violence in our study, the finding which is contrary to Mugala \& Imataa (2007) who found domestic violence as the most common reason for violence. The reasons for the high incidence of criminal violence in the present study may be due to harsh economic climate, rising unemployment rate, ineffective law enforcement and failure of successful poverty eradication programmes in Tanzania. In the present study, domestic conflicts ranked second of the reasons for the violence. However for women, domestic violence was responsible for two thirds of the admissions and the attacker were mainly husbands and ex-partners. It is likely that violence between partners in a relationship may be triggered by numerous factors, including stressful or frustrating life situations such as loss of a job, financial problems or pregnancy; role changes that may impact the attacker's sense of control. Use of alcohol and/or drug abuse, which may increase abusive behaviour, is another common cause. Attitudes and traditional beliefs on the part of the aggressor that rationalize abuse are very common in Africa. Even sadistic personality of some aggressors may be the cause (Stuart, 2004; Mugala \& Imataa, 2007). However, in this study, details of the actual causes of the conflicts at home were not established.

A better knowledge of the type of weapon or means through which violence is inflicted is of great importance for medico-legal purposes. Blunt objects such as stones, iron bars, sticks and bottles and sharp objects such as machetes, knives, axes and screw drivers were the most common weapons used in the present study. This is contrary to findings of a study in Zambia where fists, slaps and kicks were the means through which violence was 
inflicted (Mugala \& Imataa, 2007). High incidence of gunshot injuries in this study calls for urgent firearms control surveillance in this region.

In this study, it was noted that the majority of intentional injuries occurred during night hours. Similar nocturnal prevalence had been reported by Weaver et al. (1995). Night may have afforded the perpetrator the cover of darkness to make their identification difficult, it is also a period when their targets (victims) are more likely to be at home.

The pre-hospital care of trauma patient has been reported to be the most important factor in determining the ultimate outcome after the injury (Mohamed et al., 2005; Hugenberg et al., 2007; Kobusingye, 2008). The lack of advanced pre-hospital care in Mwanza and ineffective ambulance system for transportation of patients to hospitals are a major challenges in providing care for trauma patients in and have contributed significantly to poor outcome of these patients due to delay in definitive treatment.

This study showed that mostly the head and neck and upper extremities were affected which is in contrary to other studies (Mohamed et al., 2005; Ogunlusi at al., 2006; Udosen et al., 2006; Kalemoglu et al., 2006) which reported lower extremities as the most common site and attributed this phenomenon to the intent to demobilize victims. Knowing the pattern of anatomical site distribution of the injury allows the clinicians to understand the nature of intent of the perpetrator and this is of great importance for medico-legal purposes. Many lower limb injuries indicate a desire to immobilize victims while injuries involving the head, neck, chest and abdomen indicate a desire to kill (Udosen et al., 2006; Kalemoglu et al., 2006). Many patients with head and neck injuries in this study is attributed to the intent to kill the victim and associated upper limb injuries were sustained as the victims were trying to protect themselves from head injuries. Associated neck injuries may be attributed to intent to commit suicide.

Most of patients in this study sustained soft tissue injuries and long bone fractures. Similar injury patterns were also reported by other authors (Mohamed et al., 2005; Ogunlusi et al., 2006; Udosen et al., 2006). A good knowledge of the nature and type injury allows the clinicians to understand the type weapon used and this is of great importance for medicolegal purposes and surgical treatment. In agreement with other studies done elsewhere (Persad, 2005; Ojo, 2008), wound sepsis was the most common complication of treatment of intentional injuries in the current study. Therefore, early and meticulous wound care is of great importance in the management of intentional injuries.

Prolonged hospitalization, need for major surgeries and the cost of care were the major cause of morbidity in this study. The lack of efficient emergency health care services for pre-hospital care and rapid transport of injured victims to hospital which results in possibly 'preventable deaths' are also major factors contributing to increased morbidity and mortality resulting from intentional injuries in our environment. The current study had a mortality rate of $13.3 \%$, which is slightly higher than the rate reported by other authors (Kalemoglu et al., 2006). The highest mortality was recorded among patients with chest and cranio-cerebral injuries. Although limb injuries were not associated with any mortality, they were associated with serious morbidity related to prolonged duration of hospital stay. The average amount of hospital bill for each patient in the present study was US\$ 305 which is 9.2 times the official urban poverty income for Mwanza city (US\$ 33.3 per month). A person whose income is below the poverty line would have to set aside all his household income for at least 9 months just to pay the average hospital bill. The financial impact puts the family of the injured in a desperate situation, which may itself lead to a vicious cycle of crime. 
In conclusion, this study showed that intentional injuries are an emerging but neglected epidemic in Mwanza City and have become a major cause of morbidity and mortality among young males in a society where resources for pre-hospital and hospital trauma care are limited, and interpersonal violence mainly criminal and domestic violence are the major causes of these injuries. Poverty, lack of education, unemployment, alcohol and substance misuse and unequal distribution of wealth have found to be responsible for increasing incidence of intentional injuries in our environment. Establishment of efficient emergency health care services for pre-hospital care and effective ambulance system for rapid transport of injured victims to hospital will reduce morbidity and mortality associated with these injuries. Urgent preventive measures targeting at the root causes of violence such as poverty, unemployment, and alcohol abuse will reduce the incidence of these injuries in our setting.

\section{Acknowledgements}

The authors would like to thank all those who contributed effectively to the preparation of this manuscript. Special thanks go to our resident doctors in the Department of Surgery for data collection and management of our study patients.

\section{References}

Ben, J.S., Philayrath, P., Dale, B., Genevieve, P., Mercedes, G., Drew, H., Tien, C., Adrian, E.B. (2008) Intentional injury reported by young people in the Federated States of Micronesia, Kingdom of Tonga and Vanuatu. BMC Public Health 8, 145-53

Cubbin, C. \& Smith, G. (2002) Socioeconomic inequalities in injuries. Annual Reviews of Public Health 23, 347-375.

Hugenberg, F., Odhiambo, W.A., Mwita, A. \& Opondo, D. (2007) Firearm Injuries in Nairobi, Kenya: Who Pays the Price? Journal of Public Health Policy 28, 410-419

Kalemoglu, M., Yildirim, I., Keskin, O., Eryilmaz, M. \& Ersanli, D. (2006) The gunshot injuries in emergency surgery. Balkan Military Medical Review 2, 56-58.

Kobusingye, O.C. (2008) Violence and Injuries: What Africa should do. African Health Monitor 37-40.

Krug, E.G., Dahlberg, K.L., Mercy, J.A., Zwi, A.B. \& Lozano, R. (2002) World report on Violence and Health Geneva, Switzerland: World Health Organization.

Lule, E., Rosen, J.E., Singh, S., Knowles, J.C. \& Behrman, J.R (2006) Adolescent health programs. In Disease Control Priorities in Developing Countries 2nd edition. New York: Oxford University Press, 1109-1126.

Luna, G., Adye, B., Haun-Hood, M., Berry, M., Taylor, L. \& Thorn, R. (2001) Intentional injury treated in community hospitals. American Journal of Surgery 181, 463-465.

Mohammed, A.Z., Edino, S.T., Ochicha, O. \& Umar, A.B. (2005) Epidemiology of gunshot injuries in Kano, Nigeria. Nigerian Journal of Surgical Research 7, 296-299.

Moshiro, C., Ivar, H., Anne, N., Philip, S., Yusuf, H., Gunnar, K (2005) Injury morbidity in an urban and a rural area in Tanzania: an epidemiological survey BMC Public Health 5, 11.

Mugala, D.D. \& Imataa, D. (2007) Admissions for Physical Violence in Chingola -Zambia. East and Central African Journal of Surgery 12, 68-73. 
Museru, L.M., Leshabari, M.T., Grob, U. \& Lisokotola, L.N.M. (1998) The pattern of injuries seen in patients in the orthopaedic/trauma wards of Muhimbili Medical Centre. East and Central African Journal of Surgery 4, 15-21.

Mutasingwa, D.R. \& Aaro, L.E. (2001) Injury registry in developing country. A study based on patients' record from four hospitals in Dare Salaam, Tanzania. Central African Journal of Medicine 47, 203-209.

Mutto, M., Lett, R., Lawoko, S., Nansamba, C. \& Svanstrom, L. (2010) Intentional injuries among Ugandan youth: a trauma registry analysis. Injury Prevention 16, 333-336.

Ogunlusi, J.D., Oginni, L.M. \& Ikem, I.C. (2006) Gunshot injuries in a Nigerian hospital. Nigerian Journal of Orthopaedics and Trauma 5, 34-37.

Ojo, E.O., Ibrahim, A. G., Alabi, S. \& Obiano, S.K. (2008) Gunshot injuries in a North-eastern Nigerian Tertiary Hospital. The Internet Journal of Surgery 16, 2.

Omoniyi, A.O. \& Eme, T.O. (2007) Incidence and pattern of injuries among residents of a rural area in South-Western Nigeria: a community-based study. BMC Public Health 7, 246-252.

Onuminya, J.E., Ohwowhiagbese, E. (2005) Pattern of civilian gunshot injuries in Irrua, Nigeria. South African Journal of Surgery 4, 170-172.

Nordberg, E. (2000) Injuries as a public health problem in Sub-Saharan Africa: epidemiology and prospects for control. East African Medical Journal 77, S1-S43.

Persad, I.J., Reddy, R.S., Sanders, M.A. \& Patel, J. (2005) Gunshot injuries to the extremities: experience of a UK trauma centre. Injury 36, 407-411.

Said, H.S., Nyakiamo, J. \& Faya, S. (2002) Gunshot injuries as seen at the Aga Khan Hospital, Nairobi, Kenya. East African Medical Journal 79, 188-192.

Solagbem, B.A. (2003) Epidemiology and outcome of gunshot injuries in a civilian population in West Africa. European Journal of Trauma 29, 92-96.

Stone, D.H., Jeffrey, S., Dessypris, N., Kyllekidis, S., Chishti, P., Papadopoulos, F.C. \& Petridou, E.T. (2006) Intentional injury mortality in the European Union: how many more lives could be saved? Injury Prevention 12, 327-332.

Stuart, P. (2004) Risk factors for recent domestic physical assault in patients presenting to the emergency department. Emergency Medicine Australasia 16, 3, 216.

Udosen, A.M., Eliuma, A.U., Ugare, G.A. \& Bassey, O.O. (2006) Gunshot injuries in Calabar, Nigeria: an indication of increasing societal violence and police brutality. African Health Science 6, 170-172.

Warers, H., Hydes, A., Rajkotia, Y., Basu, S., Rahwinkel, J.A. \& Butchart, A. (2004) The economic dimensions of interpersonal violence. Geneva, Switzerland: World Health Organization.

Weaver, L.D., Hansraj, K.K. \& Idusuji, O.B. (1995) Gunshot injuries: frequency and cost analysis in South Central Los Angeles. Orthopedic Clinic of North America 26, 1-7.

Wolde, A., Abdella, K., Ahmed, E., Tsegaye, F., Babaniyi, O.A., Kobusingye, O. \& Bartolomeos K. (2008) Pattern of Injuries in Addis Ababa, Ethiopia: A One-year Descriptive Study. East and Central African Journal of Surgery 13, 14-22.

Zhao, Y., Guthridge, S., Magnus, A., Vos, T. (2004) Burden of disease and injury in Aboriginal and non-Aboriginal populations in the Northern Territory. Medical Journal of Australia 180, 498-502. 